\title{
A specific ovarian tumor protein isoform is required for efficient differentiation of germ cells in Drosophila oogenesis
}

\author{
Wayne R. Steinhauer ${ }^{1}$ and Laura J. Kalfayan \\ Department of Biochemistry and Biophysics, The University of North Carolina at Chapel Hill, Chapel Hill, \\ North Carolina 27599 USA
}

\begin{abstract}
Mutations within the ovarian tumor (otu) gene result in abnormal ovarian development. It has been proposed that otu phenotypes result from abnormal germ cell division and differentiation. To understand better what role otu performs in oogenesis we have undertaken an analysis of protein expression from the otu locus. Anti-otu antibodies recognize two proteins from Drosophila ovary extracts with apparent molecular masses of 98 and $104 \mathrm{kD}$. Sequence analysis of otu cDNAs suggests that these proteins are translated from two mRNAs generated by alternative splicing of a 126-bp exon between the sixth and seventh exon of the smaller transcript. Analysis of otu protein expression in eight mutants indicates a correlation between the accumulation of the 104-kD isoform and predifferentiated germ cells and suggests that there is a developmental shift in the accumulation of the two isoforms upon differentiation of germ cells. Furthermore, the 104-kD isoform appears to be required for efficient differentiation of germ cells. Immunostaining of otu proteins is restricted to the cytoplasm of germ cells, and a rapid loss of oocyte immunostaining during stage 11 suggests that there is a rapid and selective degradation of otu proteins within the oocyte but not within its 15 interconnected nurse cells.
\end{abstract}

[Key Words: ovarian tumor; oogenesis; alternative splicing; developmental regulation; differentiation]

Received September 4, 1991; revised version accepted December 13, 1991.

Drosophila has evolved a highly efficient means of synthesizing the large quantities of mRNA and protein required in early embryogenesis prior to the onset of zygotic transcription. The adaptation involves the generation of an egg chamber consisting of an oocyte and 15 germ-line-derived nurse cells that are connected to one another by cytoplasmic bridges. The nurse cells perform a trophic function, that is, their polyploidization dramatically increases the synthetic capacity within the egg chamber. The basic structure of an egg chamber is laid down in the germarium: The daughter of a stem cell la cystoblast) proceeds through 4 successive and incomplete mitotic divisions to generate a 16 cell cyst, which is then surrounded by a layer of somatically derived follicle cells. The 16 cells or cystocytes are connected in a specific arrangement by structures termed ring canals (King et al. 1956; Brown and King 1964; Kinderman and King 1973); one cystocyte will develop as an oocyte, and the remaining 15 differentiate as nurse cells. Before the egg chamber leaves the germarium and enters the vitellarium, mitotic germ cell division within the egg chamber ceases and differentiation of cystocytes is initiated.

\footnotetext{
${ }^{1}$ Present address: Laboratory of Genetics, National Institute of Environmental Health Sciences, Research Triangle Park, North Carolina 27709 USA.
}

The development of the egg chamber toward a mature egg as it progresses along the vitellarium has been subdivided into 14 morphological stages /King et al. 1956; Cummings and King 1969; Mahowald and Kambysellis $1980)$. In the previtellogenic stages (1-7), the nurse cells undergo many rounds of endomitotic DNA replication and actively synthesize RNA and proteins that are transported to the oocyte through the ring canals (King 1970; Mahowald and Kambysellis 1980; Mulligan and Rasch 1985). In the vitellogenic stages (8-14), the oocyte increases rapidly in size. A significant portion of this increase is contributed by nurse cells, which continue to increase in size through stage 10 and then rapidly transfer their cytoplasm to the oocyte during stage 11 . In the final stages of oogenesis, nurse cell nuclei degenerate and somatically derived follicle cells complete the formation of the egg membranes and their associated structures.

Thus, oogenesis entails a highly specialized pattern of cell divisions and the differentiation of cystocytes along the different developmental pathways of nurse cells and oocytes. To understand better how these processes are controlled, we have undertaken a molecular analysis of the ovarian tumor (otu) gene, mutations of which disrupt these processes. The otu gene is a potentially promising candidate for a molecular analysis of oogenesis, because otu mutants display a remarkable range of ovarian 
pathologies. Seventeen ethylmethane sulfonate (EMS)induced, and 13 P-element-induced, or P-element-derived, otu mutants have been recovered /Gans et al. 1975; Mohler 1977; Digan 1980; King and Riley 1982; King et al. 1986; Mulligan et al. 1988; G. Sass and D. Mohler, unpubl.). The phenotypes displayed by otu mutants are divided into three developmental classes that highlight specific steps within oogenesis which may be affected by or under the control of the otu gene (King et al. 1986). An otu mutant is classified by the predominant phenotype displayed within the ovary; however, multiple phenotypes may be present in any given ovary.

The quiescent (QUI) class is the most severe and represents mutants in which germ cells fail to proliferate, causing ovarioles to appear as empty sheaths of somatic tissue (King and Riley 1982). Mutants from the oncogenic (ONC) class have lost the ability to control cystocyte divisions: the usual four incomplete rounds of $\mathrm{mi}$ tosis are replaced by complete and continued cell divisions, giving rise to tumorous egg chambers filled with hundreds of undifferentiated cystocytes (King 1979). The differentiated (DIF) class encompasses mutants with ovaries that predominantly contain egg chambers exhibiting some form of differentiation. Cystocyte divisions are not always precise, and some alleles exhibit odd numbers of nurse cells or no oocyte. Those egg chambers that contain oocytes usually proceed through oogenesis to what has been called a "pseudo-12"(p12) stage but do not complete development (King et al. 1986; Storto and King 1988).

Initial molecular characterization of the otu gene and its products identified a predominant $3.2-\mathrm{kb}$ ovary-specific transcript (Mulligan et al. 1988). Sequence analysis suggested that otu generated a single 811-amino-acid protein with a $12 \%$ proline content. Here, we describe a second otu protein isoform expressed in ovaries that is generated through alternative splicing and examine alterations in expression of the two isoforms in eight otu mutants. Our results suggest that a specific isoform is required for efficient differentiation of the germ cells and that differentiation may bring about a shift in the expression of the two protein isoforms. Immunolocalization of otu proteins in situ suggests that otu is a germ cell-specific cytoplasmic protein and that its expression is differentially regulated between nurse cells and oocytes through a rapid and selective degradation of otu protein within the oocyte at stage 11 .

\section{Results}

Two protein isoforms are evident from analysis of otu gene products

Previous sequence analysis of the otu gene and several otu cDNAs suggested that otu produced a single protein of 811 amino acids (Steinhauer et al. 1989). We raised polyclonal antibodies that recognize two specific regions of this otu gene product: amino acids 253-671 and 670811. Coding regions used in lac Z-otu fusion constructs are shown below a schematic representation of an otu cDNA (Fig. 1A). The unmodified expression vector (pWR590) produces a truncated form of $\beta$-galactosidase with a molecular mass of $\sim 80 \mathrm{kD}$ (Fig. 2, lane 2), whereas fusion proteins produced from constructs 1 and 2 have masses of $\sim 140$ and $90 \mathrm{kD}$, respectively (Fig. 2, lanes $3,4)$.

Rabbit polyclonal antibodies against the two domains of otu protein were purified on fusion protein-affinity columns to generate anti-otu(253-671)- and antiotu(670-811)-specific antisera. Antisera specificities were examined in Escherichia coli extracts and in crude

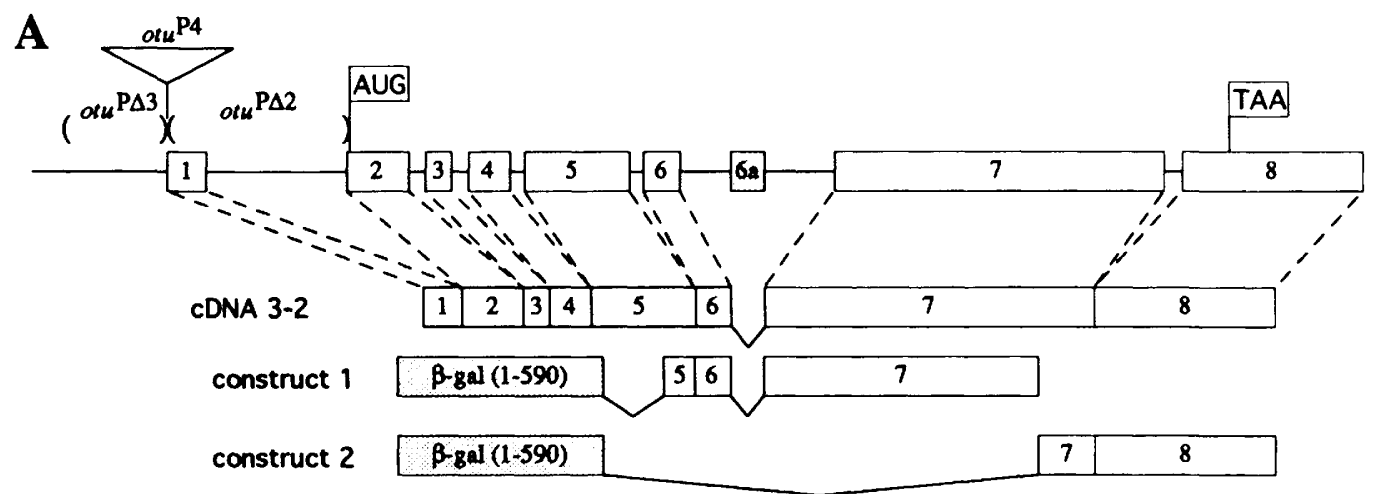

B

CDNA 4-1

\begin{tabular}{|l|l|l|l|l|l|l|l|}
\hline 1 & 2 & 3 & 4 & 5 & 6 & 64 & 7 \\
\hline
\end{tabular}

Figure 1. The structures of otu cDNAs and fusion proteins. $(A)$ The otu gene structure with translation initiation and termination sites indicated is shown above the schematic exon structure of cDNA 3-2. Approximate locations of lesions from three P-elementinduced or -derived mutations are shown at the $5^{\prime}$ end of the otu gene. The coding sequences of the otu gene ligated into the pWR 590 expression vector are identified in constructs 1 and $2 .(B)$ Schematic exon structure of cDNA 4-1. Differences between cDNA 4-1 and cDNA 3-2 include the lack of 68 nucleotides from cDNA 3-2 at the 5' end of cDNA 4-1, the truncation of cDNA 4-1 at an internal EcoRI site of cDNA 3-2, and the addition of an alternate exon (6a) in cDNA 4-1 between exons 6 and 7 of cDNA 3-2. 


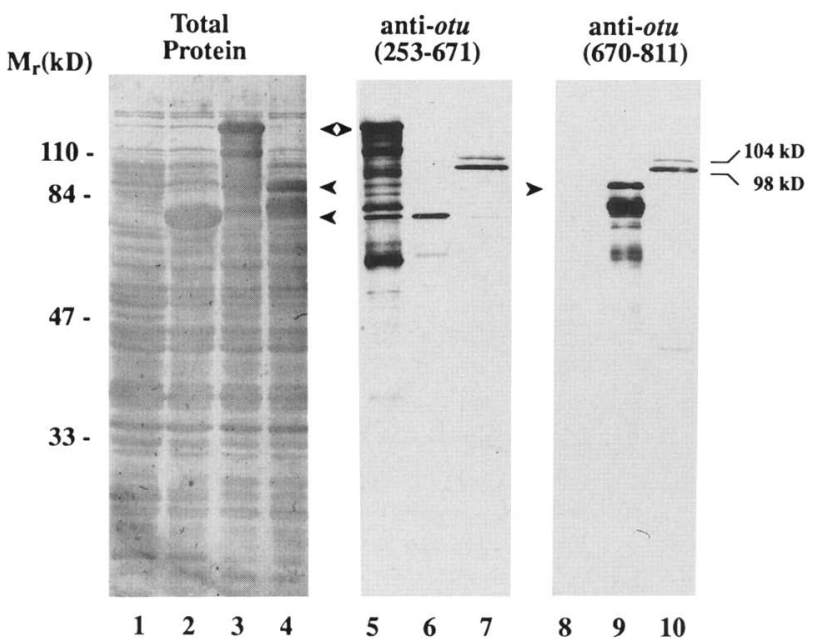

Figure 2. Analysis of the specificity of two anti-otu antisera. (Lanes 1-4) Total protein staining of E. coli extracts after fractionation by SDS-PAGE and transfer to nitrocellulose. The positions of the proteins expressed from the original expression vector (lane $2,80 \mathrm{kD}$ ), and the two fusion constructs: lacZ$o t u(253-671)$ (lane 3, $140 \mathrm{kD}$ ) and lacZ-otu(670-811) (lane 4, 90 $\mathrm{kD}$ ) are indicated by arrowheads. (Lane 1) An extract of the parent $E$. coli strain (MV1184) without an expression vector; (lanes 5-7; 8-10) Equivalent blots of extracts from E. coli expressing lacZ-otu(253-671) (lanes 5, 8), lacZ-otu|670-811) (lanes 6,9 ), or $10 \mu \mathrm{g}$ of crude ovary extract from Canton-S flies (lanes 7,10 ). Lanes $5-7$ and $8-10$ were incubated with antiotu(253-671) and anti-otu(670-811) antisera, respectively. The immunostaining proteins below the intact fusion proteins (lanes 5,9$)$ appear to be degradation products of the fusion proteins. Two proteins from Canton-S ovary extracts (at 104 and 98 $\mathrm{kD}$ ) immunostain with both antisera. The light immunostaining at $\sim 45 \mathrm{kD}$ (lane 10 ) appears to be nonspecific staining of the highly abundant vitellogenin proteins from the ovary extracts. The positions of molecular mass markers are shown at left.

extracts prepared from Drosophila ovaries. In addition to recognizing the $140-\mathrm{kD}$ fusion protein generated from construct 1 (Fig. 2, lane 5), anti-otu(253-671) antiserum cross-reacts with an $\sim 80-\mathrm{kD} E$. coli protein and a protein of similar size in ovary extracts (Fig. 2, lanes 6,7); however, as expected, this antiserum does not cross-react with the $90-\mathrm{kD}$ fusion protein generated from construct 2 (Fig. 2, lane 6). Anti-otu(670-811) antiserum recognizes the $90-\mathrm{kD}$ fusion protein and does not cross-react with the $140-\mathrm{kD}$ fusion protein (Fig. 2, lanes 8,9 ). Both antisera recognize two proteins with apparent molecular masses of 98 and $104 \mathrm{kD}$ in crude ovary extracts from wild-type (Canton-S) flies (Fig. 2, lanes 7,10). The apparent mobility of the $98-\mathrm{kD}$ protein is in reasonable agreement with the calculated molecular mass from the amino acid sequence $(92.6 \mathrm{kD})$, assuming that the high proline content of the otu protein $(12 \%)$ reduces mobility (Carroll and Scott 1985; Gaul et al. 1987; Driever and Nüsslein-Volhard 1988; Prost et al. 1988).

In support of these results an additional cDNA clone (4-1) was isolated and sequenced that begins 68 nucle- otides downstream from the $5^{\prime}$ end of cDNA $3-2$, and extends 3 ' to the internal EcoRI restriction site of cDNA 3-2 (Steinhauer et al. 1989; Fig. 1B). This cDNA does not contain a poly $(\mathrm{A})$ tract, and its termination at the EcoRI restriction site is probably a result of incomplete methylation of the cDNAs during the construction of the library.

The sequence of cDNA 4-1 revealed an additional exon (6a) located between the sixth and seventh exons of previously identified cDNAs (Champe and Laird 1989; Steinhauer et al. 1989). The additional 126-bp exon extends from nucleotide 2780 to 2905 of the otu genomic sequence (Figs. 1 and 3). Inclusion of this exon does not disrupt the translational reading frame and results in the addition of 42 amino acids (Fig. 3, 1A-42A) to the 811amino-acid otu isoform (Steinhauer et al. 1989). The peptide translated from this additional exon contains 33\% charged residues and maintains the hydrophilic character of the rest of the protein. If the transcript used to generate cDNA 4-1 was equivalent to cDNA 3-2 in the 3' region beyond the EcoRI restriction site, then the calculated molecular mass of the protein $(97.4 \mathrm{kD})$ is in reasonable agreement with the mobility of the 104-kD isoform observed in Western blots, with the assumption that proline content affects mobility.

Further support for two isoforms is the identification of a molecular lesion at the splice acceptor site for the alternate exon in an otu mutant allele that accumulates the $98-\mathrm{kD}$ isoform only in ovary extracts (see below). These data suggest that two proteins are derived from the otu gene and that the $98-\mathrm{kD}$ protein is considerably more abundant than the $104-\mathrm{kD}$ polypeptide in normal ovary extracts.

\section{Several otu mutants exhibit alterations} in the expression and/or size of otu proteins

We wished to know whether any of the ovarian pathologies of otu mutants could be correlated with specific alterations in expression of the two otu isoforms. The expression of otu proteins in selected alleles was examined by Western blot (see below). This analysis led us to sequence specific genomic regions of four otu mutants. The two ONC mutants otu ${ }^{11}$ and $o t u^{13}$ were sequenced across the alternate exon and because these mutations were induced in the same parental chromosome, sequence differences between these two alleles should identify mutations rather than background polymorphisms. A 408-bp genomic fragment of $o t u^{11}$ and otu ${ }^{13}$ that includes the alternate exon (Fig. 3, nucleotides 2643-3050) was amplified by polymerase chain reaction (PCR), and the amplified DNA was sequenced. Genomic sequence of $o t u^{13}$ indicated a $\mathrm{G} \rightarrow \mathrm{A}$ base substitution at nucleotide 2779 (Fig. 3). This transition alters the $3^{\prime}$ splice acceptor site adjacent to the $5^{\prime}$ end of the alternate exon by converting the invariant AG dinucleotide, required for splice acceptor site function, to AA. The genomic sequence of $o t u^{11}$ contained a $\mathrm{G} \rightarrow \mathrm{A}$ base substitution at nucleotide 2793 , which converts the cysteine at 


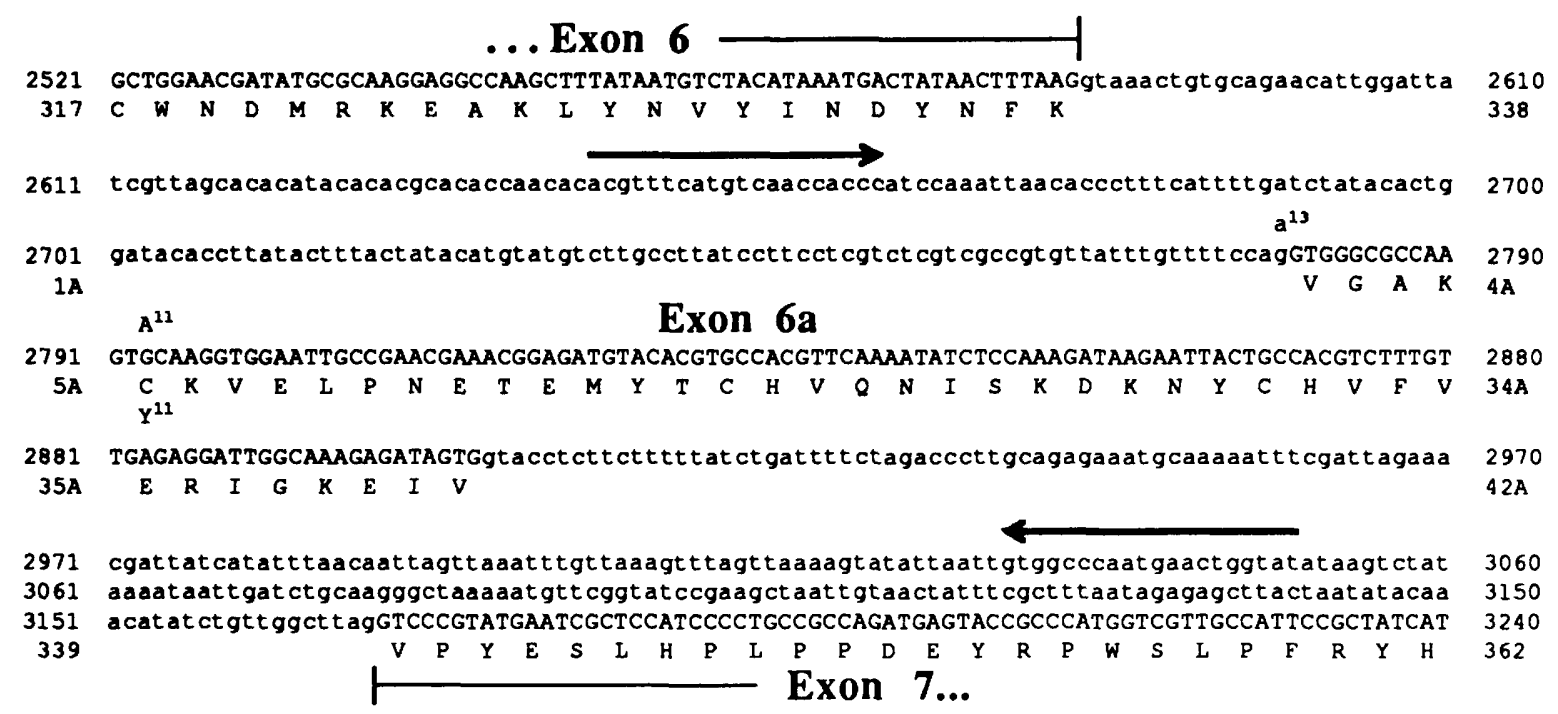

Figure 3. The nucleotide and amino acid sequence of the region that includes the alternate exon of the otu gene. The location of the alternate exon of cDNA 4-1, between exons 6 and 7 of the transcript reported previously, is identified within a portion of the otu genomic sequence (Steinhauer et al. 1989). The intron sequences are in lowercase and the alternate exon amino acids are identified as $1 \mathrm{~A}-42 \mathrm{~A}$. The location of the primers used to perform PCR amplification on the genomic fragments of otu ${ }^{11}$ and otu ${ }^{13}$ across the alternate exon are indicated by arrows. The point mutation of $o t u^{11}$ is at nucleotide $2793\left(\mathrm{~A}^{11}\right)$ and converts the wild-type cysteine to tyrosine $\left(\mathrm{Y}^{11}\right)$. The mutation within the $o t u^{1.3}$ allele is at nucleotide $2779\left(\mathrm{a}^{1.3}\right)$, which disrupts the splice acceptor site for the alternate exon.

amino acid $5 \mathrm{~A}$ to tyrosine (Fig. 3). A third ONC mutant $\left\langle o t u^{P \Delta} \Delta\right\}$ is known to have a deletion of $\sim 450$ bp upstream of the cDNA start site but has an unaltered coding region (G. Sass et al., in prep.; Fig. 1A).

Of the four ONC mutants examined by Western blot, three $\left(o t u^{11}\right.$, ot $u^{3}$ and $o t u^{P \Delta 3}$; Fig. 4, lanes 2, 4, 5) accumulate higher proportions of the larger protein, although the absolute amount of both isoforms is reduced dramatically in two of these mutants (Fig. 4, lanes 4,5 ). In the case of otu ${ }^{P \Delta 3}$ the $98-\mathrm{kD}$ isoform is either not expressed or is expressed below the level of detectability. In contrast, the ONC allele otu ${ }^{13}$ (Fig. 4, lane 3 ) displays nearly wild-type levels of protein but does not accumulate detectable levels of the 104-kD isoform. The absence of the larger isoform is expected because of the splice site mutation at the alternate exon of $o t u^{13}$. These data suggest that ONC mutants are correlated with reduced amounts of the $98-\mathrm{kD}$ isoform with respect to the normal abundance of this isoform in wild-type ovaries.

As with $o t u^{11}$ and otu ${ }^{13}$ two DIF alleles otu $u^{5}$ and otu ${ }^{14}$ were sequenced within specific regions of the otu gene. Because both ot $u^{5}$ and $o t u^{14}$ accumulate smaller proteins, it seemed likely that these alleles contained nonsense mutations. On the basis of sizes of the truncated proteins in $o t u^{5}$ and $o t u^{14}$ extracts, an estimate was made of the region within the otu gene where premature translation termination signals might be located. Fragments with 219 bp of genomic DNA (nucleotides 39474166; Steinhauer et al. 1989) from otu ${ }^{5}$ and $o t u^{14}$ were PCR amplified, cloned, and sequenced. Sequences of both mutants contained $\mathrm{C} \rightarrow \mathrm{T}$ base substitutions that created stop codons in exon 7, after residue 621 of $o t u^{5}$ and residue 655 of $o t u^{14}$ (numbered with respect to the 98-kD isoform).

Antiserum that recognizes the carboxy-terminal region of otu proteins does not recognize otu proteins in

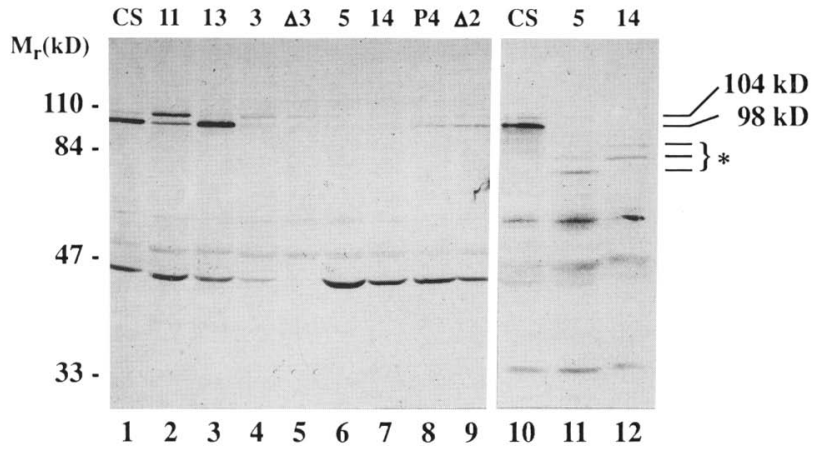

Figure 4. Western analysis of otu mutants. Eight mutants were analyzed, four ONC alleles $\left[o t u^{11}\right.$ (lane 2), ot ${ }^{13}$ (lane 3), ot $u^{3}$ (lane 4), otu $u^{P \Delta 3}$ (lane 5)], and four DIF alleles lotu (lanes 6 and

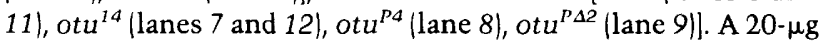
aliquot of ovary extract was loaded for each mutant, except for $o t u^{5}$ where $40 \mu \mathrm{g}$ was loaded, and $10 \mu \mathrm{g}$ of wild-type (Canton-S) ovary extract was loaded in lanes 1 and 10 . Lanes $1-9$ were incubated with anti-otu(670-811) antisenum; lanes 10-12 were incubated with anti-otu(253-671) antiserum. The two otu protein isoforms identified in Fig. 2 are indicated (104 and $98 \mathrm{kD})$, and truncated forms of these proteins from the otu $u^{5}$ and $o t u^{14}$ alleles are identified by the asterisk $\left({ }^{*}\right)$. Note that these truncated forms are not recognized by the anti-otu(670-811) antiserum (lanes 6,7$)$. The positions of molecular mass markers are shown at left. 
extracts derived from otu ${ }^{5}$ and $o t u^{14}$ (Fig. 4, lanes 6, 7). However, in extracts from both mutants, antiserum that recognizes the central portion of the otu proteins (amino acids 253-671) immunostains two proteins with lower molecular masses than the native otu proteins. In $o t u^{5}$ extracts, 82- and 76-kD polypeptides were detected (Fig. 4 , lane 11 , whereas in otu ${ }^{14}$ extracts, $86-$ and $81-\mathrm{kD}$ polypeptides were observed (Fig. 4, lane 12). Calculated molecular masses for the two isoforms are 77.2 and 72.3 $\mathrm{kD}$ for $o t u^{5}$, and 80.6 and $75.8 \mathrm{kD}$ for $o t u^{14}$. These calculated sizes are consistent with the respective masses observed, again with the assumption that proline content affects mobility. Two other DIF mutants, ot $u^{P 4}$ and $o{ }^{P \Delta 2}$ (Fig. 4, lanes 8, 9), exhibit the same sized otu polypeptides as wild-type flies but at considerably reduced levels. In contrast to the ONC mutants, DIF mutants appear to maintain a more nearly wild-type ratio of the two isoforms with respect to each other.

The truncated proteins of $o t u^{5}$ and $o t u^{14}$ are capable of promoting the early stages of oogenesis, suggesting that 190 amino acids of the carboxyl terminus are not required for proper cyst formation or differentiation. Inability of these mutants to complete oogenesis may be the result of a loss of function associated with the carboxy-terminal domains but could also result from low protein levels as seen in the Western blot, a result of reduced stability of the truncated proteins. Table 1 summarizes the phenotypes and molecular lesions associated with the otu alleles examined.

\section{Fertile heteroallelic combinations alter otu protein expression}

Although most heteroallelic combinations of otu yield intermediate phenotypes, the two ONC alleles that express relatively high levels of otu protein $l o t u^{11}$ and $o t u^{13}$ ) complement several DIF alleles to fertility. Most of these transheterozygotes have ovaries that contain substantial numbers of tumorous chambers or chambers lacking oocytes, but the chambers that form properly complete development and produce fertile eggs. The exception is the $o t u^{11} / o^{14} u^{14}$ heterozygotes, which have nearly normal ovarian morphology (Storto and King 1987). Using the DIF alleles otu ${ }^{5}$ and $o t u^{14}$ and the antiotu(670-811) antiserum that does not recognize the truncated proteins from these alleles, we examined the effects of these DIF alleles on the accumulation of otu proteins expressed from $o t u^{11}$ and $o t u^{13}$ alleles in transheterozygotes.

Heteroallelic combinations of $o t u^{5}$ and $o t u^{14}$ with $o t u^{11}$ alter the ratio of the accumulated levels of the two protein isoforms generated from the ot $u^{11}$ allele. Whereas $o t u^{11}$ homozygotes exhibit nearly equal or greater amounts of the $104-\mathrm{kD}$ isoform in comparison to the smaller isoform (Fig. 5, lane 2; Fig. 4, lane 2), heterozygotes $\left(o t u^{5} / \mathrm{otu}^{11}\right.$ and $\left.o t u^{14} / \mathrm{otu}^{11}\right)$ accumulate levels of the two isoforms at nearly wild-type ratios in which the $98-\mathrm{kD}$ isoform is predominant (Fig. 5, lanes 3-6). No change in accumulation of otu protein isoforms is observed in heteroallelic combinations of $o t u^{13}$ with $o t u^{5}$ and $o t u^{14}$ (Fig. 5, lanes 9-12). This result is as expected because of the splice site mutation at the alternate exon of $o t u^{13}$. These results suggest that the relative ratio of otu isoforms expressed from the $o t u^{11}$ allele is a function of the ovarian phenotype and that the high level of the $104-\mathrm{kD}$ isoform expressed in homozygotes is a result of the large percentage of tumorous chambers in these ovaries.

\section{Localization of otu protein in Canton-S and mutant alleles}

We examined the temporal and spatial distribution of otu proteins in wild-type and otu mutant ovary tissue sections by immunocytochemistry. Immunostaining was evident in cytoplasm of cystocytes, nurse cells, and oocytes, but no otu protein was detected in nuclei or follicle cells. Intense immunostaining is present in ger-

Table 1. Selected alleles of the otu locus and their associated lesions

\begin{tabular}{|c|c|c|c|c|}
\hline \multirow[b]{2}{*}{ Allele } & \multirow[b]{2}{*}{ Class } & \multicolumn{2}{|c|}{ Ovarian phenotypes } & \multirow[b]{2}{*}{ Molecular lesion } \\
\hline & & homozygotes & hemizygotes & \\
\hline$o t u^{11}$ & ONC & tumorous & tumorous & $\begin{array}{l}\mathrm{G} \rightarrow \text { A substitution at position } 2793 \text {; Cys } \rightarrow \text { Tyr transition at } \\
\text { position } 5 \mathrm{~A} \text { of alternate exon }\end{array}$ \\
\hline$o t u^{13}$ & ONC & tumorous & tumorous & $\begin{array}{l}\mathrm{G} \rightarrow \text { A substitution at position } 2779 ; \text { alters the splice } \\
\text { acceptor at the } 5^{\prime} \text { end of exon } 6 \mathrm{a}\end{array}$ \\
\hline$o t u^{3}$ & ONC & tumorous & quiescent & unknown \\
\hline$o t u^{P \Delta 3}$ & ONC & tumorous & quiescent & $\approx 450$-bp deletion $5^{\prime}$ of cDNA $3-2$ start site (Fig. 1A) \\
\hline$o t u^{5}$ & DIF & differentiated & quiescent & $\begin{array}{l}\mathrm{C} \rightarrow \mathrm{T} \text { substitution at position } 4018 ; 190 \text {-amino-acid } \\
\text { truncation after residue } 621\end{array}$ \\
\hline$o t u^{14}$ & DIF & differentiated & differentiated & $\begin{array}{l}\mathrm{C} \rightarrow \mathrm{T} \text { substitution at position } 4120 ; 156 \text {-amino-acid } \\
\text { truncation after residue } 655\end{array}$ \\
\hline$o t u^{P 4}$ & DIF & differentiated & ND & $\approx 500$-bp insertion near cDNA 3-2 start site (Fig. lA) \\
\hline$o t u^{P \Delta 2}$ & DIF & differentiated & tumorous & $\begin{aligned} \approx & 700 \text {-bp deletion } 3^{\prime} \text { of cDNA } 3-2 \text { start site (Fig. } 1 \mathrm{~A} \text { ); deletes } \\
& \text { most of the } 5^{\prime} \text {-untranslated leader sequence }\end{aligned}$ \\
\hline
\end{tabular}

Position numbers are as in Fig. 3 and Steinhauer et al. (1989). Residue numbers for the truncated proteins are with respect to the 98 -kD isoform. (ND) Not determined. 


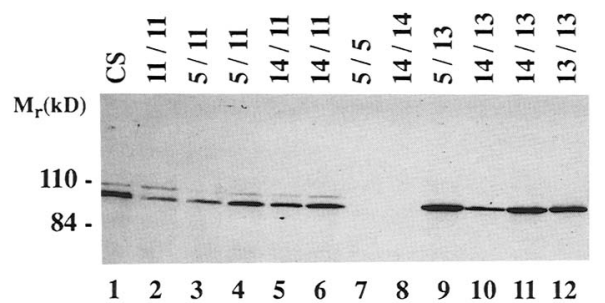

Figure 5. Western analysis of heteroallelic combinations of otu mutant alleles. Heteroallelic combinations were made of two ONC mutants (otu $u^{11}$ and $o t u^{13}$ ) with each of two DIF mutants $\left(o t u^{5}\right.$ and $\left.o t u^{14}\right)$. The genotypes of the flies from which the ovary extracts were made are indicated above each lane. Only the wild-type Canton-S (CS), ot $u^{11}$, and $o t u^{13}$ alleles express otu proteins, which can be recognized by the antiserum used to probe this Western blot. Lane 1 has $10 \mu \mathrm{g}$ of ovary extract loaded; the other lanes have either $20 \mu \mathrm{g}$ (lanes $2,3,5,7,8,10,12$ ) or $40-\mu \mathrm{g}$ (lanes $4,6,9,11$ ) loaded. The $40 \mu \mathrm{g}$ loadings compensate for heterozygotes with only one allele that expresses recognizable protein.

maria of wild-type ovaries, and staining intensity remains constant or decreases slightly through stage 4 (Fig. 6 A). From stage 5 or 6 , staining intensity increases steadily to a plateau at stages $9-10 \mathrm{~B}$. Staining is lost in nurse cells gradually and follows the degeneration of these cells. In contrast, otu protein in oocytes is degraded beyond detectability during stage 11 (Fig. 6B), a stage that lasts only $0.4 \mathrm{hr}$ (David and Merle 1968; Mahowald and Kambysellis 1980). Control tissues incubated with antisera, in which otu-specific antibodies had been removed by passing the sera over a fusion protein-affinity column, displayed very low levels of immunostaining (Fig. 6C).

Results of an immunostaining analysis of otu proteins in $o t u^{11}$, otu $u^{13}$, and $o t u^{14}$ were in agreement with the Western analysis concerning levels of protein accumulation. Staining was severely reduced in the DIF mutant $o t u^{14}$, while two ONC mutants, otu ${ }^{11}$ and ot $u^{13}$, displayed considerable staining (Fig. 6D-F). Furthermore the ONC mutants exhibit more intense staining in differentiated chambers than in tumorous chambers (Fig. $6 \mathrm{D}, \mathrm{E})$. This may reflect greater expression from polyploid nuclei of differentiated cystocytes or may be the result of smaller cytoplasmic volume in tumorous chambers. Germaria of $\mathrm{otu}^{14}$ ovaries immunostain, but there is no increase in the levels of staining as oogenesis progresses and staining is very weak in later stages (Fig. $6 \mathrm{~F}$ ). This weak staining may indicate an instability of the truncated proteins expressed from the ot ${ }^{14}$ allele.

\section{Discussion}

Alternative splicing of otu pre-mRNA generates
two protein isoforms upon translation

We have described a cDNA from the otu locus that contains an extra exon between the sixth and seventh exons of the transcript reported previously (Steinhauer et al. 1989|. Antibodies raised against fusion proteins gener- ated with two different regions of otu-coding sequences each recognize two protein isoforms of sizes that correspond to the molecular masses predicted by the conceptual translation of the two cDNAs. Western analysis showed that both isoforms were altered in otu mutants, either in mobility or relative abundance. Particularly convincing evidence for the relevance of both bands is the absence of the larger isoform in $o t u^{13}$ and truncation of both isoforms in $o t u^{5}$ and $o t u^{14}$. Each of these alterations has been correlated with a point mutation that disrupts a splice junction of the alternate exon (ot $u^{13}$ ) or creates a nonsense mutation $\left(o t u^{5}\right.$ and $\left.o t u^{14}\right)$. The splice site mutation in $o t u^{13}$ prevents appropriate splicing of the alternate exon that results in the absence of the larger isoform in $o t u^{13}$ ovary extracts. Although these three alleles have not been sequenced across the entire otu-coding region, the correlation of a specific point mutation with a predicted observable change in protein expression on Western blots is strong evidence that the identified lesions are responsible for the mutant phenotypes of these alleles. We conclude that two protein isoforms are derived from otu by an alternative splicing mechanism.

\section{A shift in protein expression may coincide with cystocyte differentiation}

Our results show a shift in accumulation of one otu protein isoform over the other that may coincide with differentiation of the germ cells. If a correlation exists between the state of differentiation and the expression of a specific otu isoform, then the ratio of the two isoforms in an extract will be a function of the degree of differentiation of germ cells within the ovary. Therefore, amounts of a specific isoform in extracts from ovaries with varying degrees of differentiation cannot be directly compared. For instance, ovary extracts from DIF mutants (mostly differentiated germ cells), which may be expressing greater amounts of the $104-\mathrm{kD}$ isoform in predifferentiated germ cells than ONC mutants (mostly undifferentiated germ cells), may still accumulate less of this isoform because of the greater percentage of predifferentiated germ cells in ONC mutants. Therefore, only the total level of expression of both isoforms and the relative ratio of the two isoforms can be compared between phenotypes. Furthermore, the ratio of the isoforms in a specific mutant will not be constant because of variability in the degree of differentiation in different extracts. For instance, the two different extracts of otu ${ }^{11}$ ovaries (Fig. 4, lane 2; Fig. 5, lane 2) show varying ratios of the two isoforms, which presumably reflects varying degrees of differentiation in these ovary preparations. We have shown that ovary extracts from otu mutants, characterized by greater percentages of undifferentiated germ cells within their ovaries than wild-type flies, exhibit correspondingly greater ratios of the $104-\mathrm{kD}$ isoform to the $98-\mathrm{kD}$ isoform, whereas otu alleles characterized by more normal percentages of differentiated germ cells within their ovaries showed more normal ratios of the two isoforms. Moreover, when we experimentally alter 

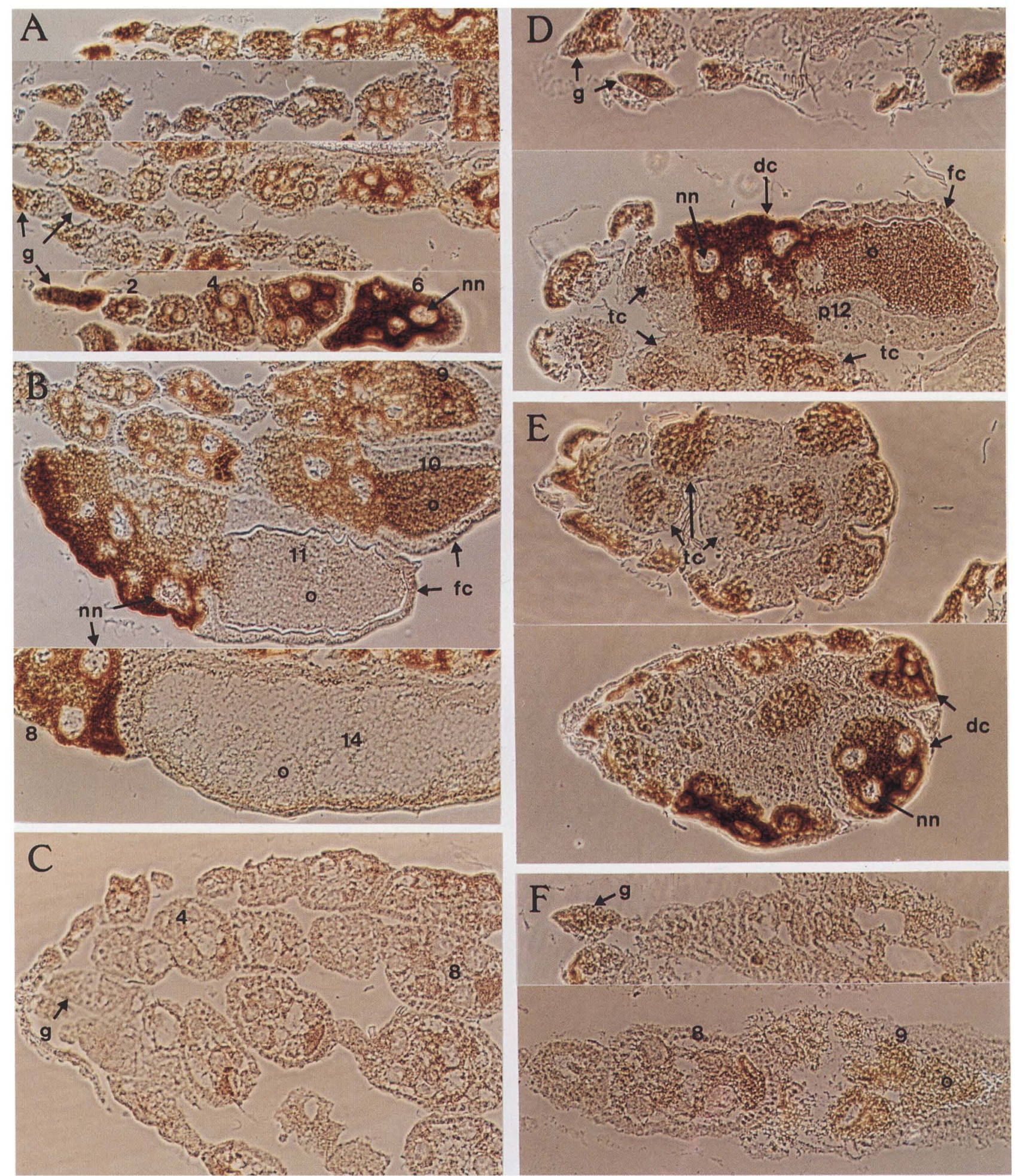

Figure 6. In situ localization of otu proteins in wild-type (Canton-S) and otu mutant ovaries. Frozen sections $(6 \mu \mathrm{m})$ were incubated with anti-otu $(670-811)$ antiserum $(A, B, D, E)$, control antiserum $(C)$, or anti-otu(253-671) antiserum $(F)$. Localization of otu proteins was accomplished by the avidin-biotin peroxidase complex technique. $(d c)$ Differentiated egg chamber; $(f c)$ follicle cells; $(g)$ germarium; $(n n)$ nurse cell nuclei; $(o)$ oocyte; $(p 12)$ psuedo-12-stage egg chamber; $(t c)$ tumorous chamber. Numbers within egg chambers represent the developmental stage of the egg chamber. $(A-C)$ Sections from wild-type (Canton-S) ovaries exhibit germarial staining and strong cytoplasmic staining in nurse cells and oocytes. Oocyte staining has disappeared by stage $11(B)$. (C) Most of the immunostaining is removed by passing anti-otu(670-811) antiserum over a lacZ-otu(670-811) affinity column prior to incubation with the sections. (D) Sections from otu ${ }^{11}$ ovaries exhibit moderate staining in germaria and tumorous chambers and strong staining in differentiated egg chambers. $(E)$ Immunostaining in $o t u^{13}$ ovaries is similar to that of otu ${ }^{11}$ ovaries. $(F)$ Sections from otu ${ }^{14}$ ovaries exhibited light germarial staining, but no significant accumulation of otu proteins is seen in later stages of oogenesis as is seen in wild-type ovaries. 
the degree of differentiation of the ovaries in which an $o^{o t u}{ }^{11}$ allele is present through heteroallelic combinations, a shift in the ratio of the two isoforms results (i.e., the pattern of expression from the ${ }^{2} u^{11}$ allele is shifted from a predominance of the 104-kD isoform in homozygotes to a predominance of the $98-\mathrm{kD}$ isoform in $\mathrm{otu}^{11}$ / $o t u^{5}$ and otu ${ }^{11} / o^{14} u^{14}$ heterozygotes).

Although it appears likely, we cannot conclude that normal undifferentiated germ cells express only the 104$\mathrm{kD}$ isoform, because ovaries of most ONC alleles contain both differentiated and undifferentiated chambers. However, the ONC allele $o t u^{P \Delta 3}$, which has unaltered coding sequences (Fig. 1 and Table 1) and contains only undifferentiated germ cells (G.Sass, unpubl.), does not accumulate detectable levels of the $98-\mathrm{kD}$ isoform. The accumulated data suggest that differentiation of cystocytes into nurse cells and an oocyte alters the splicing pathway of otu pre-mRNA, shunting splicing toward removal of the alternate exon. This is not to say that expression of the $98-\mathrm{kD}$ isoform brings about differentiation of cystocytes but is a result of that differentiation. Alternatively, differentiation could affect the stability of one mRNA or protein species more than the other.

\section{A model for otu expression}

It has been proposed that the otu gene product is required in increasing amounts throughout oogenesis and that different classes of otu mutants reflect phenocritical thresholds of functional otu protein expression (King and Riley 1982; King et al. 1986). The fact that heteroallelic combinations of some ONC alleles with some DIF alleles yield fertile flies rather than flies with intermediate ovarian pathologies suggests that a second otu product exists and that each complementing allele provides one of the required functions (Storto and King 1987). It is remarkable that the hypothesis developed by King and his collegues from genetic and morphological analyses should, for the most part, predict observed molecular data so closely.

The three developmental classes (QUI, ONC, and DIF) that categorize otu phenotypes highlight three stages of oogenesis where otu gene products appear to have a major function: stem cell proliferation, control of germ cell divisions and differentiation, and oocyte development. The first two stages require only low levels of otu expression as evidenced by the reduced levels of otu proteins in two of the ONC mutants and all of the DIF mutants examined. Furthermore, the threshold of expression that separates the ONC and DIF phenotypes appears to be very narrow because among mutants that have unaltered coding regions, DIF mutants accumulate only slightly greater amounts of otu products than ONC mutants. Several observations lead us to conclude that later stages of oogenesis require greater accumulation of otu protein for normal oocyte development. First, results from an in situ analysis suggest that otu proteins accumulate to high levels in nurse cells of stage 11 egg chambers. Second, all DIF mutants examined accumulate much less protein than wild-type flies. The molecular lesions in $o t u^{5}$ and $o t u^{14}$ result in truncated otu proteins; and by immunocytochemical analysis $\left(o t u^{14}\right)$, the truncations appear primarily to destabilize the proteins and prevent their accumulation in later stages of oogenesis. Finally, heteroallelic crosses of $o t u^{14}$ with ONC alleles are fertile when the ONC alleles express high levels of otu proteins $\left(o t u^{11}\right.$ and $\left.o t u^{13}\right)$, but are sterile when the ONC alleles express low levels of otu proteins $\left(o t u^{3}\right.$ and $\left.o t u^{P \Delta 3}\right)$. Thus, the termination of oogenesis around stage 12 in otu $^{14}$ mutants can be overcome by providing a stable and abundant source of the $98-\mathrm{kD}$ isoform.

We have suggested that a shift in expression coincides with differentiation of germ cells, but is there a requirement for a specific isoform at any specific stage of oogenesis? The control of cyst formation and differentiation appears to be sensitive to which otu isoform is expressed, as suggested by the observations outlined here. (1) Two ONC mutants otu ${ }^{11}$ and otu ${ }^{13}$ accumulate high levels of otu protein and yet give rise to tumorous ovaries, a more severe ovarian pathology than that of the DIF mutants examined, which accumulate much less otu protein. (2) Point mutations, which affect the alternate exon $(6 \mathrm{a}$ ) and, hence, the 104-kD isoform, have been identified in both ot $u^{11}$ and otu ${ }^{13}$. (3) Truncated otu proteins are expressed from two DIF alleles otu $u^{5}$ and $o t u^{14}$, which presumably have normal alternate exons, yet these truncations have little discernible effect on cyst formation or differentiation. Moreover, otu ${ }^{11}$ and otu ${ }^{13}$ presumably produce perfectly functional $98-\mathrm{kD}$ isoform and generate fertile flies when crossed with otu ${ }^{5}$ or otu ${ }^{14}$, which can provide otu function through differentiation. These data in conjunction with the evidence that the $104-\mathrm{kD}$ isoform is the predominant otu protein in undifferentiated cystocytes suggest that this isoform plays an important role in controlling the early mitotic divisions of oogenesis. Although the larger isoform appears to be important for controlling these early divisions and generating normal cysts, it is not absolutely required for cystocyte differentiation, because ot $u^{1.3}$ lacks this isoform entirely and yet produces some differentiated chambers. Perhaps high levels of the $98-\mathrm{kD}$ isoform can promote cystocyte differentiation inefficiently.

Our present hypothesis is that the 104-kD isoform is expressed early in oogenesis and is required for proper control of germ cell divisions. The onset of differentiation results in an alternative splice such that the $98-\mathrm{kD}$ isoform is expressed in stages subsequent to differentiation and that this isoform accumulates progressively in germ cell cytoplasm through stage 11, except in oocytes where it is rapidly degraded at the beginning of stage 11 . These latter stages of oogenesis presumably require high levels of otu protein, as low levels result in the termination of development.

\section{How might otu function?}

Proteins from otu appear to play an important role in at least three different processes of oogenesis: stem cell proliferation, control of germ cell divisions, and degeneration and collapse of the nurse cells. In light of the 
distribution of otu protein in ovaries (i.e., in germ-cell cytoplasm/ we think the most likely function of otu is in controlling cytoskeletal reorganizations. The high level of otu protein in ovaries suggests the possibility that these proteins are integral components of specific cytoskeletal structures. However, otu proteins could also affect cytoskeletal reorganization by a number of alternatives.

Two studies support the idea that otu proteins perform a cytoskeletal role. The characteristic branched structure of 16-cell cysts is thought to be generated by a structure known as a polyfusome, which occupies the ring canals of the cyst (Maziarski 1913; Koch and King 1969; Mahowald and Strassheim 1970; Mahowald 1971; Telfer 1975; King and Storto 1988). Examination by electron microscopy and reconstruction of serial sections of germaria from the ONC mutant $o t u^{1}$ revealed that this mutant could not sustain a series of arrested cleavages and that its fusomal material contained ultrastructural differences from normal polyfusomes (Storto and King 1989). It was suggested that otu gene products are involved in the organization and maintenance of ring canals through stabilization of the polyfusome, and if differentiation of cystocytes is linked to appropriate cyst formation then a disruption of the polyfusome could result in continued cell division and a tumorous phenotype. Nurse cell cytoplasmic transport is arrested in the DIF mutant $\mathrm{otu}^{7}$, and this mutant lacks a network of actin microfilaments in nurse cells (Storto and King 1988), which are proposed to provide contractile forces that transport nurse cell cytoplasm into the oocyte through the ring canals (Gutzeit 1986). Interestingly, rapid loss of otu immunostaining in oocytes of normal egg chambers is coincident with development of actin filament networks in nurse cells and the cytoplasmic transport process. If otu gene products perform a role in organizing the microfilament network perhaps degradation of otu protein in oocytes is required to prevent similar networks from forming in oocytes.

Although these cytoskeletal anomalies cannot account for the entire spectrum of otu mutant phenotypes, they provide insight into the function of otu proteins during oogenesis and a direction for studies of protein interactions with otu gene products.

\section{Materials and methods}

\section{Antibody generation and purification}

Production of anti-otu(253-671) antiserum has been described previously (Steinhauer et al. 1989). Anti-otu(670-811) antiserum was produced by inserting a $3^{\prime}$ EcoRI restriction fragment of cDNA 3-2 (nucleotides 4161-5177 excluding the intron; Steinhauer et al. 1989) into the pWR590 expression vector (Guo et al. 1984). The lacZ-otu fusion construct was used to transform $E$. coli MV1 184 cells. The expressed $90-\mathrm{kD}$ fusion protein was partially purified by insoluble aggregation /Williams et al. 1982; Rio et al. 1986) and then gel purified by SDS-PAGE. Protein bands were visualized by Coomassie staining in water, excised, electroeluted, and precipitated with 8 vol of ethanol. Precipitated protein $(50-200 \mu \mathrm{g})$ was resuspended in a buffer containing $50 \mathrm{~mm}$ Tris- $\mathrm{HCl}(\mathrm{pH} 8.0), 0.2 \%$ SDS, and $0.3 \mathrm{M} \mathrm{NaCl}$, emulsified in an equal volume of Freund's complete adjuvant, and injected in multiple subcutaneous sites of rabbits. Rabbits were boosted at 3-week intervals with protein prepared as described above, emulsified in an equal volume of Freund's incomplete adjuvant.

Affinity columns were prepared with both fusion proteins by coupling to Affi-gel $10(1 \mathrm{mg}$ of protein $/ \mathrm{ml}$ of gel), following the manufacturer's specifications (Bio-Rad). Coupling buffer was $0.1 \mathrm{M} \mathrm{NaHCO}_{3}$ (pH 8.5), $0.3 \mathrm{M} \mathrm{NaCl}$, and when required, $0.2 \%$ SDS was included to keep the fusion protein in solution. Addition of SDS in the coupling buffer did not interfere with coupling. High-titer sera were affinity purified on a lacZ-otul670811 ) fusion protein-affinity column following removal of antibodies against $\beta$-galactosidase on a lacZ-otu(253-671) fusion protein column. Loadings, washes, and elutions followed the procedures described by Robbins et al. (1984).

\section{Sequence analysis}

cDNA 4-1 was excised from $\lambda$ gt 11 (Huynh et al. 1985) by EcoRI digestion and inserted into EcoRI-digested Ml3mp8 (Messing 1983). The cDNA consists of two EcoRI fragments resulting from what appears to be a single-base change at nucleotide 2516 (Steinhauer et al. 1989), creating an additional EcoRI site. Nucleotide sequences were determined by the dideoxy chain-termination method (Sanger et al. 1977) on M13 single-stranded phage templates. The complete sequence of the alternate cDNA was determined on one strand by using oligonucleotide primers designed from the published sequence (Steinhauer et al. 1989). Sequences were assembled and analyzed with the University of Wisconsin Genetics Computer Group programs (Devereux et al. 1984).

Western analysis

Ovaries were dissected from 2- to 6-day-old females that had been fed on yeast paste for 2 days at $18^{\circ} \mathrm{C}$. Ovaries were homogenized in buffer containing $50 \mathrm{~mm}$ Tris- $\mathrm{HCl}(\mathrm{pH} 7.5), 3 \mathrm{~mm}$ EDTA, $1 \%$ NP-40, 0.1\% SDS, $1 \mathrm{mM} \mathrm{N}$-ethylmaleimide, $100 \mu \mathrm{M}$ leupeptin, $10 \mu \mathrm{M}$ pepstatin, 3 trypsin inhibitor units (TIU) of aprotinin $/ \mathrm{ml}$, and $100 \mu \mathrm{g} / \mathrm{ml}$ PMSF and centrifuged at $13,000 \mathrm{~g}$ for $3 \mathrm{~min}$. Protein concentrations of the supernatants were determined by the method of Bradford (1976). Protein recoveries were typically 5-10 $\mathrm{g}$ /ovary from Canton-S or otu DIF alleles and $0.5-1 \mu \mathrm{g} / \mathrm{ovary}$ from otu ONC alleles.

Samples containing $10-20 \mu \mathrm{g}$ of protein were mixed with equal volumes of $2 \times$ sample buffer (Laemmli 1970) and fractionated on $10 \%$ SDS-polyacrylamide gels $(1.5 \mathrm{~mm})$. Proteins were blotted to nitrocellulose overnight by electrophoretic transfer (Towbin et al. 1979). Efficiency of transfer was estimated by transfer of prestained molecular mass markers (BioRad). Blots were blocked for $1 \mathrm{hr}$ with $1 \%$ BSA (Promega) in TBST [ $10 \mathrm{~mm}$ Tris- $\mathrm{HCl}$ (pH 8.0), $150 \mathrm{~mm} \mathrm{NaCl}, 0.1 \%$ Tween-20] followed by primary antibody incubation in TBST. Incubation times varied with the antibodies used [anti-otu(253-671), $1 \mathrm{hr}$; anti-otu|670-811), $3 \mathrm{hr}$. After washing four times for $10 \mathrm{~min}$ each in TBST, blots were incubated with alkaline phosphataseconjugated goat anti-rabbit secondary antibody in TBST for $1 \mathrm{hr}$ (Boehringer Mannheim, 1:5000). Blots were washed four times for $10 \mathrm{~min}$ each in TBST and developed with BCIP and nitroblue tetrazolium (Bio-Rad) following the manufacturer's specifications.

\section{PCR amplification}

Genomic DNA for PCR amplification was prepared from mutant flies by mashing three flies with a toothpick in $50 \mu \mathrm{l}$ of a 
buffer containing $10 \mathrm{~mm}$ Tris- $\mathrm{HCl}(\mathrm{pH} 8.2), 1 \mathrm{~mm}$ EDTA, $25 \mathrm{~mm}$ $\mathrm{NaCl}$, and $200 \mu \mathrm{g} / \mathrm{ml}$ of proteinase $\mathrm{K}$. Homogenates were heated to $95^{\circ} \mathrm{C}$ for $15 \mathrm{~min}$ and, after addition of $2 \mu \mathrm{l}$ of $10 \mathrm{mg} / \mathrm{ml} \mathrm{PMSF}$, reheated to $65^{\circ} \mathrm{C}$ for an additional $15 \mathrm{~min}$. Homogenates were then centrifuged to pellet the debris, and the supernatant was removed. A 10- $\mu$ l aliquot of this supernatant was used in each $\mathrm{PCR}$ reaction.

PCR (Saiki et al. 1988) was performed with the GeneAmp kit (Perkin-Elmer Cetus) following the manufacturer's specifications. Reactions were cycled 30 times $194^{\circ} \mathrm{C}$ for $1 \mathrm{~min}, 55^{\circ} \mathrm{C}$ for $1 \mathrm{~min}, 70^{\circ} \mathrm{C}$ for $1 \mathrm{~min} /$, and resulting fragments were digested with EcoRI and HindIII, gel purified, and inserted into EcoRI/ HindIII-digested M13mp8 and M13mp9. Primers for amplifying across the alternate exon were ATCAAGCTT-2643-2662 (Fig. 3) and AGCGAATTC-3050-3031 (Fig. 3), which amplified a 408-bp genomic fragment from otu ${ }^{11}$ and $o t u^{13}$. The primers used to find the nonsense mutations in $o t u^{5}$ and $o t u^{14}$ were GCTAAGCTT-3947-3966 and 4197-4178 (for sequence, see Steinhauer et al. 1989). In this case, the internal EcoRI restriction site just upstream of the $3^{\prime}$ primer, along with the HindIII site in the $5^{\prime}$ primer, was used to clone the amplified 251-bp genomic fragment. Use of the internal EcoRI site resulted in the insertion of 219 bp of genomic DNA from $o t u^{5}$ and $o t u^{14}$ into EcoRI/HindIII-digested M13mp8 and M13mp9. All sequencing reactions were performed as described above.

\section{Tissue preparation and immunoperoxidase staining}

Prior to immunostaining, control antisera were generated by removal of $\mathrm{otu}$-specific antibodies on fusion protein-affinity columns. Two hundred microliters of anti-otu(670-811) antiserum was loaded onto a lacZ-otu(253-671) and a lacZ-otu|670-811) affinity column, and washed with $10 \mathrm{ml}$ of PBS containing $1 \%$ BSA, and the flowthrough was recycled over the column four times. The final flowthrough from the lacZ-otu(253-671) column was the experimental sera, whereas the flowthrough from the lacZ-otu(670-811) column served as the control sera. Similarly, $80 \mu \mathrm{l}$ of anti-otu(253-671) antiserum was loaded on affinity columns and processed as described above. Flowthrough from the lacZ-otu(670-811) column was the experimental sera, and flowthrough from the lacZ-otu(253-671) column was the control sera.

Ovaries were dissected from 2- to 6-day-old females that had been fed on yeast paste for 2 days at $18^{\circ} \mathrm{C}$. Ovaries were frozen directly in optimally controlled temperature (OCT) compound (Miles, Inc.) and sectioned $(6 \mu \mathrm{m})$ on a cryotome. Sections were mounted on glass slides coated with poly-L-lysine and air-dried at room temperature. Sections were fixed with formalin for 30 min, washed twice for $5 \mathrm{~min}$ in PBS $[10 \mathrm{~mm}$ sodium phosphate (pH 7.4), $150 \mathrm{~mm} \mathrm{NaCl}$ ), and treated with $1 \% \mathrm{H}_{2} \mathrm{O}_{2}$ in PBS for 10 min. After two rinses with PBS and a 10-min incubation with $2 \%$ lamb serum in PBS, sections were incubated for $24-48 \mathrm{hr}$ at $4^{\circ} \mathrm{C}$ with dilutions (anti-otu(253-671)(1:40); anti-otu(670-811) (1:4)] of the experimental and the control antisera in PBS containing $1 \%$ BSA. Immunoreactivity was localized by the avidinbiotin peroxidase complex technique (Hsu et al. 1981), using diaminobenzidine for formation of the reaction product.

\section{Acknowledgments}

This work is dedicated to the memory of Laura J. Kalfayan who died of cancer on May 9, 1990. I thank Chris Ingraham for technical guidance on immunocytochemistry, and Allen Comer, Georgette Sass, and Rosemary Walsh for valuable discussions. I thank Bob King, Mimi Sander, Lillie Searles, Ron Swanstrom, Alan Spradling, and Bob Voelker for constructive criticism of the manuscript. This work was funded by grant NP-657 from the American Cancer Society.

The publication costs of this article were defrayed in part by payment of page charges. This article must therefore be hereby marked "advertisement" in accordance with 18 USC section 1734 solely to indicate this fact.

\section{References}

Bradford, M. 1976. A rapid and sensitive method for the quantitation of microgram quantities of protein utilizing the principle of protein-dye binding. Anal. Biochem. 72: 248254.

Brown, E.H. and R.C. King. 1964. Studies on events resulting in formation of an egg chamber in Drosophila melanogaster. Growth 28: 41-81.

Carroll, S.B. and M.P. Scott. 1985. Localization of the fushi tarazu protein during Drosophila embryogenesis. Cell 43: 47-57.

Champe, M.A. and C.D. Laird. 1989. Nucleotide sequence of a cDNA from the putative ovarian tumor locus of Drosophila melanogaster. Nucleic Acids Res. 17: 3304.

Cummings, M.R. and R.C. King. 1969. The cytology of the vitellogenic stages of oogenesis in Drosophila melanogaster. I. General staging characteristics. J. Morphol. 128: 427-442.

David, J. and J. Merle. 1968. A re-evaluation of the duration of egg chamber stages in oogenesis of Drosophila melanogaster. Drosophila Inform Serv. 43: 122-123.

Devereux, J., P. Haeberli, and O. Smithies. 1984. A comprehensive set of sequence analysis programs for the VAX. Nucleic Acids Res. 12: 387-395.

Digan, M.E. 1980. "A genetic analysis of chorion morphogenesis in Drosophila melanogaster." Ph.D. thesis, Indiana University, Bloomington, IN.

Driever, W. and C. Nüsslein-Volhard. 1988. A gradient of bicoid protein in Drosophila embryos. Cell 54: 263-269.

Gans, M., C. Audit, and M. Masson. 1975. Isolation and characterization of sex-linked female-sterile mutants in Drosophila melanogaster. Genetics 81: 683-704.

Gaul, U., E. Seifert, R. Schuh, and H. Jäckle. 1987. Analysis of krüpple protein distribution during early Drosophila development reveals postranslational regulation. Cell :639-647.

Guo, L., P.P. Stepien, J.Y. Tso, R. Brousseau, S. Narang, D.Y. Thomas, and R. Wu. 1984. Synthesis of human insulin gene. VIII. Construction of expression vectors for fused proinsulin production in Escherichia coli. Gene 29: 251-254.

Gutzeit, H.O. 1986. The role of microfilaments in cytoplasmic streaming in Drosophila follicles. I. Cell Sci. 80: 159-169.

Hsu, S.M., L. Raine, and H. Fanger. 1981. Use of avidin-biotin peroxidase complex $(\mathrm{ABC})$ in immunoperoxidase techniques: A comparison between $\mathrm{ABC}$ and unlabeled antibody (PAP) procedures. J. Histochem. Cytochem. 29: 577-580.

Huynh, T.V., R.A. Young, and R.W. Davis. 1985. Constructing and screening cDNA libraries in $\lambda \mathrm{gt} 10$ and $\lambda \mathrm{gt} 11$. In DNA cloning techniques: A practical approach (ed. D. Glover), pp. 49-78. IRL Press, Oxford.

Kinderman, N.B. and R.C. King. 1973. Oogenesis in Drosophila virilis. I. Interactions between the ring canal rims and the nucleus of the oocyte. Biol. Bull. 144: 331-354.

King, R.C. 1970. Ovarian development in Drosophila melanogaster. Academic Press, New York.

- 1979. Aberrant fusomes in the ovarian cystocytes of the fs(1)231 mutant of Drosophila melanogaster Meigen (Diptera: Drosophilidae). Int. I. Insect Morphol. Embryol. 8: 297-309.

King, R.C. and S.F. Riley. 1982. Ovarian pathologies generated 
by various alleles of the otu locus in Drosophila melanogaster. Dev. Genet. 3: 69-89.

King, R.C. and P.D. Storto. 1988. The role of the otu gene in Drosophila oogenesis. BioEssays 8: 18-24.

King, R.C., A.C. Rubinson, and R.F. Smith. 1956. Oogenesis in adult Drosophila melanogaster. Growth 20: 121-157.

King, R.C., D. Mohler, S.F. Riley, P.D. Storto, and P.S. Nicolazzo. 1986. Complementation between alleles at the ovarian tumor locus of Drosophila melanogaster. Dev. Genet. 7: 1-20.

Koch, E.A. and R.C. King. 1969. Further studies on the ring canal system of the ovarian cystocytes of Drosophila melanogaster. Z. Zellforsch. 102: 129-152.

Laemmli, U.K. 1970. Cleavage of structural proteins during the assembly of the head of bacteriophage T4. Nature 227:680 685.

Mahowald, A.P. 1971. The formation of ring canals by cell furrows in Drosophila. Z. Zellforsch. Mikrosk. Anat. 118: 162167.

Mahowald, A.P. and J.M. Strassheim. 1970. Intercellular migration of centrioles in the germarium of Drosophila melanogaster. An electron microscopic study. I. Cell Biol. 45: 306320.

Mahowald, A.P. and M.P. Kambysellis. 1980. Oogenesis. In Genetics and biology of Drosophila (ed. M. Ashburner and T.R.F. Wright), vol. 2d, pp. 141-224. Academic Press, New York.

Maziarski, S. 1913. Sur la persistance désidus fusariaux pendant les nombreuses générations cellulaires au cours de l'ovogénese de Vespa vulgaris. L. Arch. Zellforsch. 10: 507-532.

Messing, J. 1983. New M13 vectors for cloning. Methods Enzymol. 101: 20-78.

Mohler, J.D. 1977. Developmental genetics of the Drosophila egg. I. Identification of 59 sex-linked cistrons with maternal effects on embryonic development. Genetics 85: 259-272.

Mulligan, P.K. and E.M. Rasch. 1985. Determination of DNA content in the nurse and follicle cells from wild-type and mutant Drosophila melanogaster by DNA-Fuelgen cytophotometry. Histochemistry 82: 233-247.

Mulligan, P.K., J.D. Mohler, and L.J. Kalfayan. 1988. Molecular localization and developmental expression of the otu locus of Drosophila melanogaster. Mol. Cell Biol. 8: 1481-1488.

Prost, E., F. Deryckere, C. Roos, M. Haenlin, V. Pantesco, and E. Mohier. 1988. Role of the oocyte nucleus in determination of the dorsoventral polarity of Drosophila as revealed by molecular analysis of the Kl0 gene. Genes \& Dev. 2: 891-900.

Rio, D.C., F.A. Laski, and G.M. Rubin. 1986. Identification and immunochemical analysis of biologically active Drosophila P element transposase. Cell 44: 21-32.

Robbins, A., W.S. Dynan, A. Greenleaf, and R. Tjian. 1984. Affinity-purified antibody as a probe of RNA polyemerase II subunit structure. J. Mol. Appl. Genet. 2: 343-353.

Saiki, R.K., D.H. Gelfand, S. Stoffel, S.J. Scharf, R. Higuchi, G.T. Horn, K.B. Mullis, and H.A. Erlich. 1988. Primer-directed enzymatic amplification of DNA with a thermostable DNA polymerase. Science 239: 487-491.

Sanger, F., S. Nicklen, and A.R. Coulson. 1977. DNA sequencing with chain-terminating inhibitors. Proc. Natl. Acad. Sci. 74: 5463-5467.

Steinhauer, W.R., R.C. Walsh, and L.J. Kalfayan. 1989. Sequence and structure of the Drosophila melanogaster ovarian tumor gene and generation of an antibody specific for the ovarian tumor protein. Mol. Cell. Biol. 9: 5726-5732.

Storto, P.D. and R.C. King. 1987. Fertile heteroallelic combinations of mutant alleles of the otu locus of Drosophila melanogaster. Wilhelm Roux's Arch. Dev. Biol. 196: 210-221.
1988. Multiplicity of functions for the otu gene products during Drosophila oogenesis. Dev. Genet. 9: 91-120.

. 1989. The role of polyfusomes in generating branched chains of cystocytes during Drosophila oogenesis. Dev. Genet. 10: 70-86.

Telfer, W.H. 1975. Development and physiology of the oocytenurse cell syncytium. Adv. Insect Physiol. 11: 223-319.

Towbin, H., T. Staehelin, and J. Gordon. 1979. Electrophoretic transfer of proteins from polyacrylamide gels to nitrocellulose sheets: Procedure and some applications. Proc. Natl. Acad. Sci. 76: 4350-4354.

Williams, D.C., R.M. Van Frank, W.L. Muth, and J.P. Burnett. 1982. Cytoplasmic inclusion bodies in Escherichia coli producing biosynthetic human insulin proteins. Science 215: 687-689. 


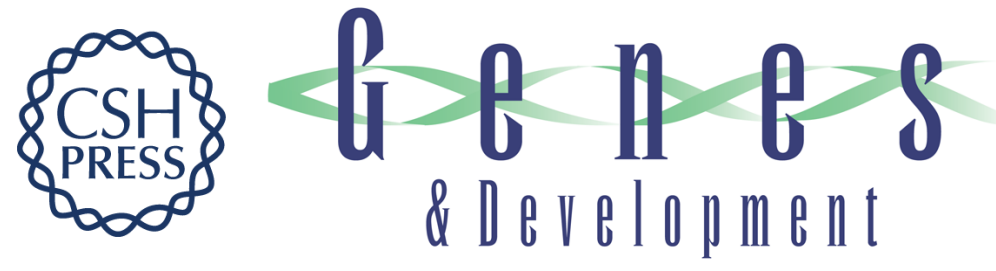

\section{A specific ovarian tumor protein isoform is required for efficient differentiation of germ cells in Drosophila oogenesis.}

W R Steinhauer and L J Kalfayan

Genes Dev. 1992, 6:

Access the most recent version at doi:10.1101/gad.6.2.233

References This article cites 38 articles, 11 of which can be accessed free at:

http://genesdev.cshlp.org/content/6/2/233.full.html\#ref-list-1

License

Email Alerting

Service

Receive free email alerts when new articles cite this article - sign up in the box at the top right corner of the article or click here.

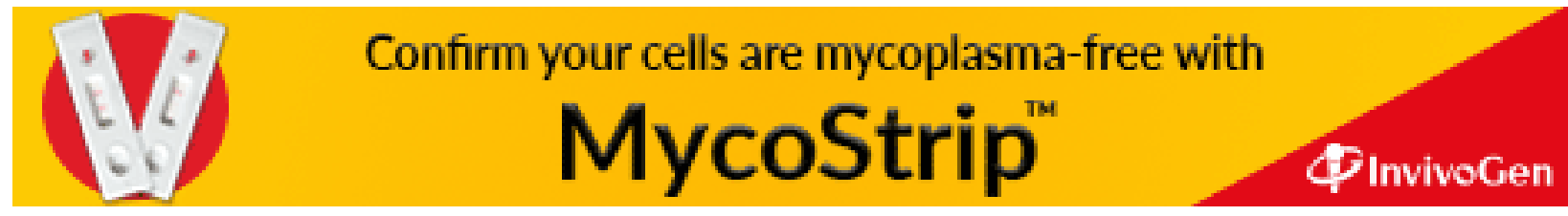

